\title{
ANÁLISIS TRIBUTARIO DE LAS COMISIONES POR SERVICIOS DE LOS AGENTES INTERMEDIARIOS TEXTILES
}

\section{TAX ANALYSIS OF COMMISSIONS FOR SERVICES OF INTERMEDIARY TEXTILE AGENTS}

\author{
Tania Belky López Siu \\ Egresada de Maestría en Política y Administración Tributaria de la Universidad Nacional Mayor de San Marcos. \\ Correo: taniabelky@gmail.com (autor corresponsal).
}

[Recibido: 2016/12/10 Aceptado: 2017/02/16]

\section{RESUMEN}

La presente evaluación permite presentar que las comisiones por los servicios de los Agentes Intermediarios Textiles, representantes de empresas del exterior, se encuentran inafectas al Impuesto General a las Ventas. A partir de dicho objetivo, se realizó un análisis descriptivo tomando en cuenta las variables materia de la investigación, obteniendo como resultados, que los ingresos por comisiones al gravar con el Impuesto General a las Ventas, representa una disminución de $15.26 \%$ de su rendimiento económico, al emitirse la factura al no domiciliado (consumidor final), el agente intermediario textil asume el impuesto disminuyendo el beneficio económico de la operación. Debido a la carencia de inclusión en la norma tributaria del Impuesto General a las Ventas del Apéndice $V$ exportación de Servicios, a este tipo de actividades les genera controversias de interpretación normativa, perjudicando la estabilidad operativa de las empresas Agentes Intermediarias Textiles y existencia de empresas confeccionistas exportadoras.

\section{PALABRAS CLAVE}

Comisiones, impuesto, ventas, intermediarios, textiles, confeccionistas, prendas de vestir

\begin{abstract}
The present evaluation allows to show that the commissions for the services of the textile intermediary agents, representatives of foreign companies, are unaffected by the general sales tax. Based on this objective, a descriptive analysis was carried out taking into account the variables of the research, obtaining as results, that the income from commissions when taxing with the general sales tax, represents a decrease of $15.26 \%$ in its economic performance, when the invoice is issued to the non-domiciled (final consumer), the textile intermediary assumes the tax by reducing the economic benefit of the operation. Due to the lack of inclusion in the tax norm of the general tax on sales of appendix $v$ export of services, this type of activity generates controversies of normative interpretation, damaging the operational stability of the companies intermediate textile agents and the existence of confectionary companies exporters
\end{abstract}

\section{KEYWORDS}

Commissions, tax, sales, intermediary, textile, confectionary, apparel garment.

Como Citar: López, T. (2017). Análisis tributario de las comisiones por servicios de los agentes intermediarios textiles. Quipukamayoc 25(48), 27-37. doi: http://dx.doi.org/10.15381/quipu.v25i48.13988 


\section{INTRODUCCIÓN}

El estudio realizó una evaluación sobre las comisiones por servicios de los Agentes Intermediarios Textiles, representantes de empresas del exterior, el tratamiento con relación a la legislación del Impuesto General a las Ventas, así como, la implicancia que origina la aplicación del mencionado impuesto a este tipo de operaciones. Para tal efecto, se formula la siguiente interrogante: ¿Las Comisiones por los servicios de los Agentes Intermediarios Textiles, representantes de empresas del exterior, se encuentran inafectas al Impuesto General a las Ventas?.

En la exportación de bienes como es el caso de las prendas de vestir, las empresas extranjeras (no domiciliadas), para adquirir dichas mercancías (importar), se sirven de empresas peruanas (domiciliadas) que actúan como agentes intermediarios, generando comisiones por estos servicios, sin embargo; la ley del Impuesto General a las Ventas, no precisa a este tipo de operaciones.

Debido a esta imprecisión normativa, ocasiona que algunas empresas Agentes Intermediarias textiles graven las comisiones por servicios como si se tratase de una operación importación, en cambio otras empresas de este tipo por la naturaleza de la operación exportación no gravan con el Impuesto General a las Ventas, ocasionándola a estas últimas, situaciones de suspensión cierre de actividades principalmente como consecuencia de deudas tributarias por este impuesto.

Es así que la hipótesis que responde a la pregunta es: Si se demuestra que las comisiones por los servicios de los Agentes Intermediarios Textiles, representantes de empresas del exterior, se encuentran inafectas al Impuesto General a las Ventas, se incrementa este tipo de servicios por comisión.
Para tal efecto, se exponen los fundamentos teóricos, doctrinarios de la normatividad de la Ley del Impuesto a las Ventas, se fundamenta que la comisión por servicios de Agentes Intermediarios Textiles cumplen los requisitos para ser considerado en el Apéndice V Exportación de Servicios. También se sustenta la teoría contable aplicada según Norma Internacional de Contabilidad 18 Ingresos operaciones ordinarias en lo que refiere a servicios; debido a la repercusión en la aplicación del Impuesto General a las Ventas, en los rendimientos y beneficios económicos en los ingresos por comisiones de las empresas Agentes Intermediarias Textiles.

Bajo tal premisa, el estudio recurre al enfoque cualitativo, por ser probatorio a través de doctrinas, normativas Contable, Tributaria, documentación de actividades de Agentes Intermediarios Textiles (manuales de procedimientos, contratos de agencia, entre otros).

Para una mejor comprensión del tema propuesto, el contenido se ha estructurado en cuatro partes. La primera comprende las bases teóricas, la segunda se plantea la metodología,la tercera la discusión y la cuarta abarcan los resultados. Luego, se presentan las conclusiones. Finalmente, se da a conocer las referencias bibliográficas.

Alva (2013) precisa que para el caso peruano la Ley del Impuesto General a las Ventas desde 1982, está realizado en base a la estructura del Impuesto al Valor Agregado (...), se gravan todas las fases del ciclo de producción y distribución hasta llegar al consumidor final, pero en cada una de estas etapas solo se paga el valor que se agrega, para el caso de las comisiones por servicios de los agentes intermediarios textiles, representantes de empresas del exterior, se da el cumplimiento del circuito económico, teniendo como consumidor final el no domiciliado. Para dar origen al nacimiento de la obligación tributaria al Impuesto General a las Ventas se tiene que tomar en cuenta la Hipótesis de Incidencia.

Según Caballero (1998) denominada así porque sugiere un hecho hipotético, abstracto, ideal que incide, impone o se pretende gravar con un tributo contenido en una norma un acontecimiento, cuyo hecho imponible o imposición da origen al nacimiento de la obligación tributaria. Es requisito indispensable para que se produzca el hecho imponible, la materialización de los cuatro aspectos de la hipótesis de incidencia: aspecto material, subjetivo, espacial y temporal, caso contrario, se estará ante un supuesto de INAFECTACION.

Las comisiones por servicios de los Agentes Intermediarios textiles, representantes de empresas del exterior, el hecho imponible o imposición al consumo nacería en los ingresos percibidos bajo comisión, cumple el aspecto material (ingreso por comisión que es la base cuantificable y medible), aspecto subjetivo (persona deudor, contribuyente o responsable, es el Agente Intermediario Textil y persona acreedor tributario entendiéndose por tal a aquél a favor del cual debe realizarse la prestación del servicio que sería el Cliente del exterior), aspecto espacial (lugar o consumo en el territorio nacional, en el caso de las comisiones por servicios de los Agentes Intermediarios Textiles, representantes de empresas del exterior, no cumple esta condición, aspecto temporal (en las comisiones por servicios de los Agentes Intermediarios Textiles, representantes de empresas del exterior, se configuraría el impuesto en la fecha que se emite el comprobante de pago o en la fecha en que se percibe la retribución, lo que ocurra primero).

Alva (2011) refiere que El Impues- 
to General a las Ventas estructurado como un Impuesto al Valor Agregado considera características técnicas, como:

- Gravamen indirecto que recae sobre el consumo.

- Su estructura busca evitar los efectos de piramidación y acumulación.

- Diseñado para facilitar el control por parte de la Administración Tributaria.

- Evita las molestas distorsiones económicas orientado a procurar la neutralidad del impuesto".

El caso de las comisiones por servicios de los Agentes Intermediarios Textiles, representantes de empresas del exterior, se considera los aspectos conceptuales, características técnicas descritos precedentemente para sustentar la inafectación al Impuesto General a las Ventas.

Principio de neutralidad: Villanueva y Gutiérrez (2014), coinciden al manifestar, "el IGV es un impuesto general al consumo de bienes y servicios cuyo principio económico fundamental es la neutralidad", para la aplicación de este principio debe cumplir lo siguiente:

- No debe asumir el costo económico, es decir, no debe impactar el Impuesto General a las Ventas en el margen de utilidad"; al afectar con el IGV a las comisiones por servicios de los agentes intermediarios textiles, representantes de empresas del exterior, repercute en los Ingresos por Comisiones, el cual mide el rendimiento de la actividad del Agente.

- La neutralidad se manifiesta en la traslación del IGV”, al gravar con Impuesto General a las Ventas los ingresos por comisión por servicios de los Agentes Intermediarios
Textiles, representantes de empresas del exterior se estaría exportando el Impuesto.

- Igualdad en el trato impositivo tanto en el consumo interno y consumo internacional de bienes y servicios"; las comisiones por servicios de los Agentes Intermediarios textiles, representantes de empresas del exterior, se origina por servicios establecido en los contratos de intermediación internacional (contratos agente de compra), que promueve la exportación del bien (productos textiles), cuyo consumo definitivo será en el extranjero.

La Comisión Mercantil según el Código de Comercio Peruano (1902), lo define en su Art. $237^{\circ}$ se reputara comisión mercantil el mandato, cuando tenga por objeto un acto u operación de comercio, y sea comerciante o agente mediador del comercio el comitente o el comisionista.

Art. $255^{\circ}$ El comisionista desempeñará por sí los encargos recibidos, y no podrá delegarlos sin previo consentimiento del comitente.

Art. $1806^{\circ}$ Comisión mercantil con representación (...) es aquella en la que el comisionista actúa con representación del comitente, es decir, que frente a terceros se presenta como un representante del comitente; $y$, por lo tanto, celebra las operaciones en su nombre e interés.

Los Contratos de Intermediación Comercial Internacional son definidos de la siguiente manera:

Obregón (2012), define "las instituciones contractuales constituyen herramientas de gran utilidad para dar seguridad jurídica al patrimonio $y$ responsabilidades de cada una de las partes que intervienen sobretodo en el comercio internacional (...), utili- zados en diferentes países y así evitar contratiempos o eventualidades que pueden menoscabar los intereses de las partes contratantes".

De la Fuente y Echarri (1999), establecen "Desde hace tiempo el empresario y las empresas han necesitado valerse de intermediarios para poder realizar actos de comercio fuera de su establecimiento (...), las operaciones comerciales son cada vez más complejas, requieren de técnicos y especialistas que conozcan bien su funcionamiento y los usos mercantiles de plazas muy diversas $(. .$.$) .$

Es necesario precisar que para que sea posible la exportación de prendas de vestir, se recurre al mecanismo de intermediación; siendo el agente intermediario textil, la empresa vinculante entre las empresas compradoras extranjeras y las empresas confeccionistas textiles, estableciéndose una relación comercial internacional bajo comisión, a través del Contrato de Agente de Compras (Contratos de Intermediación Comercial Internacional, recuperado de http://www.internationalcontracts.net/contrato/.../ contratos), detallándose a continuación.

Contrato de Agente de compras es tipo de contrato, una parte (Principal) encarga a otra (Agente de Compras), la representación y gestión de compras (ejemplo: prendas de vestir), en un territorio definido que puede ser un país o grupo de países.

Entre las funciones del Agente de Compras están: la identificación de fabricantes y suministradores de productos dentro del territorio; la negociación de precios, condiciones de entrega y de pago; la revisión de los documentos del transporte internacional para que sean conformes con los procedimientos de exportación e importación(...). 
En la investigación se observó el cumplimiento de dichas funciones entre la empresa compradora extranjera y el
Agente Intermediario textil, (ver Figura 1).
La Empresa Compradora extranjera (Principal), dedicada a la importación de prendas de vestir por temporadas

Este Contrato de la Agencia Compradora, efectivo desde (fecha) es firmado por y entre Textiles Sourcing SAC (empresa Agente intermediario nacional-domiciliada), con su oficina principal ubicada en _Lima-Perú (domicilio fiscal-Perú), quien de ahora en adelante será el "AGENTE" y The Talbots, INC (empresa compradora extranjera-no domiciliada), con su oficina principal ubicada en___Estados Unidos (domicilio fiscal-Extranjero), quien de ahora en adelante será el "PRINCIPAL".

CONSIDERANDO, que el Principal se dedica a la importación de prendas de vestir para su venta en Estados Unidos, y

CONSIDERANDO, que (Agente) actúa como representante en el Perú de las partes interesadas en los Estados Unidos, y

CONSIDERANDO, que las partes en el presente, desean celebrar un Contrato escrito que incorpore todos los previos y actuales acuerdos concerniente a la relación de la agencia entre las partes, AHORA, POR LO TANTO, en consideración de mutuas promesas y acuerdos entre las partes. En este documento, se acuerda como sigue:

(1) El Agente actuará como un Agente Comprador no exclusivo para el Principal, en lo relacionado con las compras de prendas de vestir del Principal en el Perú. El Principal acuerda que, por la duración de este Contrato, el Principal usará Agente para todos los vendedores y fábricas inicialmente pre sentadas al Principal por el Agente.

(2) El Agente acuerda realizar los siguientes servicios en nombre del Principal:

(a) El Agente deberá conocer las necesidades del Principal y hacer las averiguaciones sobre los po tenciales fabricantes con el fin de hacer contacto con los mejores fabricantes del mercado.

(b) El Agente tratará en la negociación de los precios más favorables para el Principal. Al respecto, el Agente deberá visitar fabricantes, obtener muestras de la mercadería, enviar dichas muestras al Principal, cotizar precios con a los que la mercadería puede ser comprada.

(c) El Agente colocará pedidos a fabricantes en nombre del Principal. El Agente actuará sólo bajo las específicas instrucciones del Principal; el Agente nunca actuará sin estas instrucciones explícitas. El Agente certifica que no tiene ningún derecho, poder o autoridad para hacer contrato alguno o incurrir en alguna obligación de responsabilidad que deberá ser confirmada por el Principal, a menos que haya sido específicamente autorizado por el Principal para hacerlo por adelantado. El Agente es utilizado con el propósito de adquirir artículos específicos para el Principal (...).

(3) El Principal acuerda compensar al Agente con el por ciento (_\%) del precio de la mercadería embarcada de los fabricantes/vendedores de acuerdo con este Contrato. Dicha comisión será pagada al precio FOB (Franco a Bordo) de esta mercadería (exportación de prendas de vestir). Cuando la mercadería ha sido calificada como defectuosa por el Principal, las comisiones no serán devengadas y cualquier comisión pagada relativa a esta mercadería deberá ser reembolsada por el Agente.

(4) El pago por la mercadería se hará directamente por el Principal al fabricante.

(5) El Agente deberá proporcionar al Principal una factura separada por el pago por comisiones de compra y no producción (...).

EN FÉ DE LO CUAL, las partes firman este Contrato:

POR: THE TALBOTS, INC(Principal)

POR:TEXTILES SOURCING SAC (Agente)

FIRMA: FIRMA:

Figura 1. Contrato entre Empresa Compradora Extranjera de Prendas de Vestir y Empresa Agente Intermediaria Textil. Fuente: Elaboración propia. 
(fall, spring, summer- otoño, primavera, verano), mediante manuales de procedimientos, establece los procesos a seguir en cada fase de la con- fección de prendas de vestir categoría “T-Shirt" a la empresa Agente Intermediaria Textil, con la finalidad de que las prendas a exportar por las empresas confeccionistas sean de óptima calidad (ver Figura 2).

\title{
PROCEDIMIENTOS GENERALES
}

\begin{abstract}
PANORAMA DEL PROCEDIMIENTO
Los procedimientos se aplican a las siguientes categorías de productos: Missy, ,Petite,Tall,, Womens Los procedimientos de prueba y las pautas para la fabricación de Prendas de Algodón se pueden encontrar en las siguientes fases de este manual.
\end{abstract}

El Programa para los textiles implica la realización de ensayos de productos en los puntos clave de la fabricación de la siguiente manera:

\section{Fase I: Desarrollo}

Generalmente, se realizan pruebas para proteger y asegurar el cumplimiento de los estándares de desempeño, basados en problemas específicos, riesgos potenciales de calidad y / o fabricaciones de prendas de vestir.

\section{Fase II: Muestras}

Las muestras de los productos presentadas para el ensayo deben ser representativas de las características de calidad a granel, para las propiedades sometidas a prueba. Cualquier variación debe ser reportada directamente a The Talbots, Inc (Principal), antes que las pruebas comiencen.

\section{Fase III: Producción de Telas a Granel}

The Talbots, Inc (Principal), requiere pruebas de tejido a granel, de acuerdo con el protocolo de tejido designado. Las pruebas se deben realizar en tela a granel, en colores reales a granel y con el tratamiento correcto de acabado / lavado. Además, cualquier solicitud de documentación sobre tejidos / certificados de autenticidad debe ser obtenida y enviada al personal de ensayo apropiado. La aprobación de la "Principal" debe ser alcanzada ANTES del envío de la tela de la fábrica al fabricante.

Fase IV: Producción de prendas de vestir a granel

Después de recibir las aprobaciones de tejido necesarias, las prendas de producción deben ser probadas de acuerdo con el protocolo de prendas designado. Todas las pruebas deben realizarse en los productos, ya que se venden, incluyendo el uso de componentes reales y adornos. Confirmación de cuidado y contenido será dado después de la prueba aprobada de prendas de vestir. Las aprobaciones por escrito de The Talbots, Inc (Principal), debe darse antes del envío de los productos.

Figura 2. Manual de Procedimientos- Procedimiento Generales para el Desarrollo y Confección de Prendas de Vestir - Empresa Compradora Extranjera.

Fuente: Elaboración propia.

La Empresa Compradora extranjera textil (Principal), una vez aceptada la conformidad y recibida de manera óptima las prendas de vestir (ex- portación), procede con la recepción por parte del Agente Intermediario Textil la factura (invoice) de exportación (Ley de Comprobantes de pago,
1994), (ver Figura 3, en la siguiente página); conteniendo los datos del documento aplicado a las operaciones de exportación. 


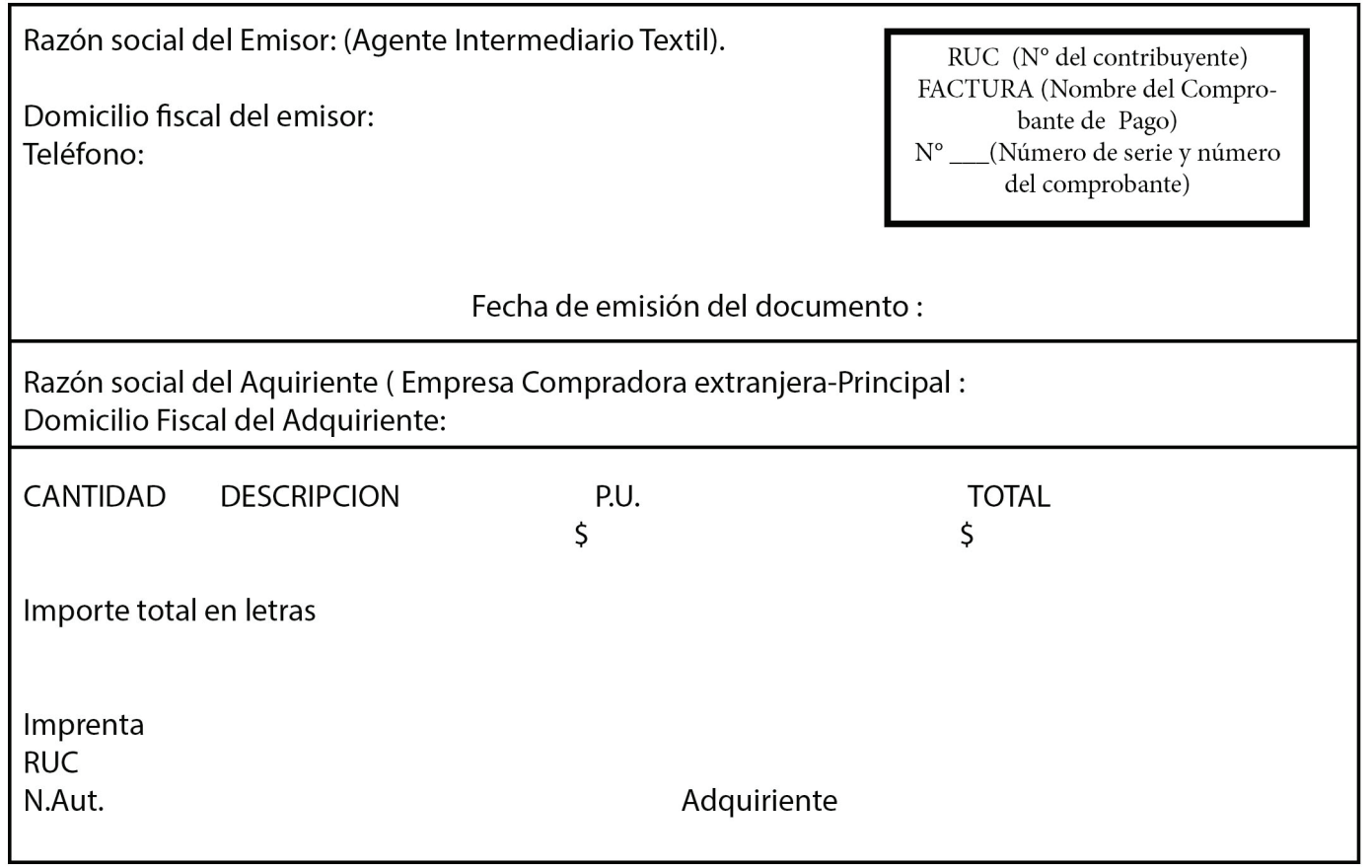

Figura 3. Factura (INVOICE), Comprobantes de Pago/exportación. Fuente: Elaboración propia.

Texto único Ordenado de la Ley del Impuesto General a las Ventas e Impuesto Selectivo al Consumo

Art. $1^{\circ}$ Operaciones gravadas El Impuesto General a las ventas grava las siguientes operaciones:

a) La venta en el país de bienes muebles (...),

b)La prestación o utilización de servicios en el país

El servicio es utilizado en el país cuando siendo prestado por un sujeto no domiciliado, es consumido o empleado en el territorio nacional, independientemente del lugar en que se pague o se perciba la contraprestación y del lugar donde se celebre el contrato.

Como se observó en la investigación, el servicio no es utilizado en el país, no es prestado por un sujeto no domiciliado, y no es consumido o empleado en el territorio nacional (...), no se cumple las condiciones para que sea una operación gravada.
Ley de fomento al comercio exterior de servicios

Definiendo la norma la Exportación de Servicios,

Art. $2^{\circ}$ Exportación de servicios

Es el suministro de un servicio de cualquier sector, a través de cualquiera de las siguientes modalidades de prestación:

1. Comercio transfronterizo: servicio que se suministra desde el territorio nacional hacia el territorio de otro país.

2. Consumo extranjero: Cuando el consumidor del servicio se desplaza y lo adquiere en el territorio nacional. 3. Presencia comercial: Cuando el proveedor domiciliado en el territorio nacional establece una sucursal o establecimiento permanente en el territorio de otro país para suministrar un servicio.

4. Presencia de personas físicas: Consiste en el desplazamiento de personas físicas domiciliadas en el territorio nacional a otro país para suministrar un servicio (...).

El caso de "Las comisiones por servicios de los Agentes Intermediarios Textiles, representantes de empresas del exterior (...)"; se considera la modalidad de servicio Comercio transfronterizo.

\section{Exportación de bienes y servicios} El artículo $33^{\circ} \mathrm{del}$ Texto Único Ordenado de la Ley del Impuesto General a las Ventas e Impuesto Selectivo al Consumo (...), no están afectos al Impuesto General a las Ventas.

Las operaciones consideradas como exportación de servicios (comercio transfronterizo), son las contenidas en el Apéndice V, (...). Tales servicios se consideran exportados cuando cumplan concurrentemente con los siguientes requisitos:

1. Se presten a título oneroso, lo que debe demostrarse con el comprobante 
de pago que corresponda (...); en la investigación, la comisión, es el título oneroso facturado a la empresa compradora extranjera

2. El exportador sea una persona domiciliada en el país. El Agente Intermediario Textil (exportador del servicio) es la empresa domiciliada.

3. El usuario o beneficiario del servicio sea una persona no domiciliada en el país;la empresa compradora extranjera de prendas de vestir (Principal), es la usuaria o beneficiaria del servicio.
4. El uso, explotación o el aprovechamiento de los servicios por parte del no domiciliado tengan lugar en el extranjero. Para el caso de la investigación los servicios (operaciones de representación a nombre del Principal - para la adquisición de prendas de vestir), son aprovechados en el exterior, debido a que el Principal va informándose de manera permanente del servicio realizado por el agente intermediario textil del seguimiento realizado al proceso de producción de la confección de las prendas con la finalidad de que exporten prendas de alta calidad para que dicho bien luego sea comercializado en el extranjero. Apéndice V: operaciones consideradas como exportación de servicios Prosiguiendo con el Art. $33^{\circ}$, de ley del Impuesto General a las Ventas, establece como exportación de servicios, las siguientes actividades, (Ver Tabla 1)

\section{Tabla 1.}

Comercio Transfronterizo

Fuente: Elaboración propia.

\section{COMERCIO TRANSFRONTERIZO}

1 Servicio de consultoría, asesoría y asistencia técnica

2 Arrendamiento de bienes muebles

3 Servicios de publicidad, investigación de mercado y encuestas de opinión pública

4 Servicios de procesamiento de datos, aplicación de programas de informática y similares (...)

5 Servicios de colocación y de suministro de personal

6 Servicios de comisiones por colocación de crédito

7 Operaciones de financiamiento

8 Seguros y reaseguros

9 Los servicios de telecomunicaciones destinados a completar el servicio, originado en el exterior (...)

10 Servicios de mediación u organización de servicios turísticos (...)

11 Cesión temporal de derechos de uso o de sujetos domiciliados en el exterior (...)

12 El suministro de energía eléctrica a favor de sujetos domiciliados en el exterior (...)

13 Los servicios de asistencia telefónica (...)

14 Los servicios de apoyo empresarial prestados en el país a empresas o usuarios domiciliados en el exterior, tales como servicios de contabilidad, tesorería, soporte tecnológico, informático o logística, centro de contacto, laboratorios y similares

\begin{tabular}{ll}
\hline 15 & Servicios de diseño \\
\hline 16 & Servicios editoriales \\
\hline 17 & Servicios de imprenta \\
\hline 18 & Servicios de investigación científica y desarrollo tecnológico \\
\hline 19 & Servicios de asistencia legal \\
\hline 20 & Servicios de audiovisuales \\
\hline
\end{tabular}

Como se observa, de manera concluyente se menciona algunos servicios de exportación, lo cual origina situación de incertidumbre a otras actividades de exportación, como es el de las Comisiones por Servicios de los Agentes Intermediarios Textiles. También se analizó la norma contable aplicable a los servicios como a continuación se detalla:

Norma Internacional de Contabilidad $N^{\circ} 18$ Ingresos de Actividades Ordina- rias - prestación de servicios

El párrafo 20 (Norma Internacional de Contabilidad $\mathrm{N}^{\circ} 18$, 2014)establece, "cuando el resultado de una transacción, que suponga la prestación 
de servicios, pueda ser estimado con fiabilidad(...)cuando se cumplen las siguientes condiciones:

(a) el importe de los ingresos de actividades ordinarias pueda medirse con fiabilidad; en la investigación, los ingresos por comisión han sido medidos como consecuencia del valor fob de exportación de prendas de vestir.

(b) sea probable que la entidad reciba los beneficios económicos asociados con la transacción;el Agente recibe los beneficios económicos asociados con la Comisión por servicios mediante la cobranza de la factura / invoice via transferencia bancaria por la conformidad del servicio.

(c) el grado de realización de la transacción, al final del periodo sobre el que se informa, pueda ser medido con fiabilidad, es decir, el grado de realización de la transacción es medido mediante el porcentaje (\%) establecido en el contrato.

Cumpliendo los criterios en la investigación.

\section{MATERIAL Y MÉTODOS}

Investigación Descriptiva y Aplicativa Teniendo como unidad de análisis se consideran a las Empresas Agentes Intermediarias Textiles, representantes del Exterior específicamente las ubicadas en Lima.

\section{RESULTADOS}

La evaluación muestra el efecto en los ingresos que causa las comisiones por servicios de los Agentes Intermediarios Textiles, representantes de empresas del exterior en la aplicación del Impuesto General a las Ventas, siendo evaluado el Valor de Comisión por servicios de Agente, descrita en la factura/invoice $\mathrm{N}^{\circ} 160$ por el monto de US\$ 25 542,70, resultante de las operaciones de exportación realizadas por las empresas confeccionistas de prendas de vestir, como a continuación se detalla:

Valor FOB (Free of Board), de expor- taciones realizadas por el confeccionista textil:

Sample'13 and production' 13 (Muestras y producción año 2013)

Muestras Temporada Fall-otoño 2013 = FOB $\$ 19,496.40 \times 3 \%$ (comisión) $=$ 584,89

Producción Temporada Spring-primavera $2013=$ FOB \$ 499 156,19 x $5 \%($ comisión $)=24957,81$

$$
\begin{array}{r}
584,89 \\
24957,81 \\
\hline \$ 25542,70
\end{array}
$$

Total comisión de servicio de agente intermediario textil \$ 25 542,70

Siendo la factura/invoice (ver Figura 4), el documento que acredita la prestación de servicios realizados por el

\begin{tabular}{|c|c|}
\hline Textiles Sourcing S.A.C. & \\
\hline $\begin{array}{l}\text { Av. La Molina Nº } 638 \text { Lima-Perú } \\
\text { Phone : } \\
\text { e-mail : } \\
\text { Fecha: } 15.01 .2013\end{array}$ & $\begin{array}{c}\text { RUC } 20514959006 \\
\text { FACTURA (Invoice) } \\
001-160\end{array}$ \\
\hline $\begin{array}{l}\text { CONSIGNEE TO: } \\
\text { The Talbots, Inc } \\
\text {-USA }\end{array}$ & \\
\hline $\begin{array}{l}\text { DESCRIPTION } \\
\text { Comisión de servicios de agente intermediario textil, } \\
\text { Representante de la empresa The Talbots, Inc. } \\
\text { Muestras y Producción temporada: } \\
\\
\text { Sample'13 and Production'13 } \\
\text { Fall'13 } \\
\text { Spring'13 }\end{array}$ & AMOUNT \\
\hline $\begin{array}{l}\text { There are : Twenty five, five hundred forty two and } 70 / 100 \text { US dollars } \\
\text { Imprenta Full Services Sac } \\
\text { RUC N }{ }^{\circ} 20554101942 \\
\text { N.Aut.187766 F.l.12.11.2012 }\end{array}$ & Adquiriente \\
\hline
\end{tabular}
Agente Intermediario Textil bajo comisión para fines tributarios.

Figura 4. Factura (INVOICE), Comisión Agente Intermediario Textil Fuente: Contrato entre Empresa Compradora Extranjera de Prendas de Vestir y Empresa Agente Intermediaria Textil. / Elaboración propia 
Sin embargo, la actividad porcomisión por servicios del Agente Intermediario Textil representante de empre-

sas del exterior, al no establecerse en la Ley del Impuesto General a las Ventas, presenta dos criterios de análisis en su aplicación:

Tabla 2.

Criterios de análisis de la Ley de Impuesto General a las Ventas

Fuente: Elaboración propia.

\begin{tabular}{lll} 
& SIN IGV & CON IGV (Recálculo) \\
INGRESO & US\$ 25 542,70 & US\$ 21646,36 \\
\hline
\end{tabular}

(Ventas por prestación de Servicios)

Para el cumplimiento de la aplicación del IGV, se procede al recálculo: US\$ 25 542,70/1,18 = US\$ 21646,36

Resultando el Impuesto General a las Ventas $18 \%$ (débito fiscal) $=$ US\$ 3896,34

El valor de US\$ 25 542,70 frente al valor de US\$ 21 646,36 representa este último el $84,74 \%$, disminuyendo el valor real del Ingreso por Comisión por Servicio de Agente; los US\$ 3 896,34 representa 15,26\%.

En términos contables esta situación estaría impactando en el Ingreso, el cual mide el rendimiento económico de la actividad.

Los resultados al estudio a "Las comisiones por Servicios de los Agentes
Intermediarios Textiles, representantes de empresas del exterior", refleja lo siguiente:

1. Los ingresos por comisiones al gravar con el Impuesto General a las Ventas, representa una disminución de $15.26 \%$ de su rendimiento económico. 2. Los ingresos por comisiones al emitir la factura/invoice a la empresa compradora textil extranjera (consumidor final) y gravar con el Impuesto General a las Ventas la operación, el Agente Intermediario Textil asume dicho impuesto.

3. Los ingresos por comisiones al gravar con el Impuesto General a las Ventas, disminuye el beneficio económico (poder adquisitivo-caja), debido a que al asumir dicho impuesto (Débito Fiscal) se procedería con el pago al Gobierno Central.

Además, en la evaluación a "Las Comisiones por Servicios de los Agentes Intermediarios Textiles, representantes de empresas del exterior, se encuentran inafectas al Impuesto General a las Ventas", determinaron que debido a la carencia de inclusión en la norma tributaria del Apéndice V Exportación de Servicios; perjudica la estabilidad operativa de las empresas Agentes Intermediarias Textiles, las cuales tuvieron la siguiente evolución, (ver Figura 4).

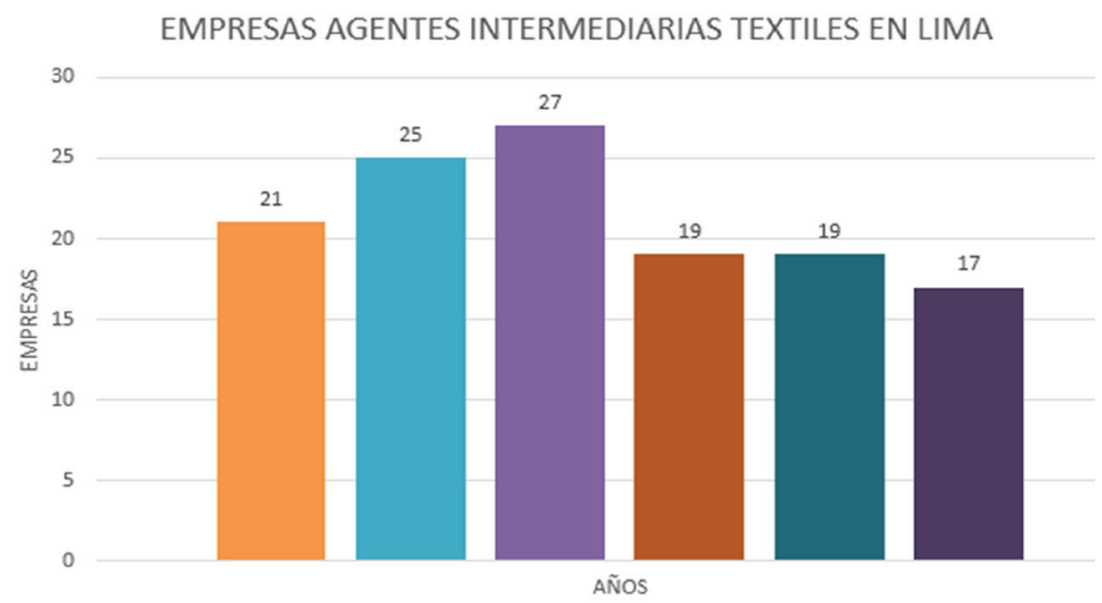

Figura 5. Empresas Agentes Intermediarias Textiles en Lima-Perú Fuente: Cámara de Comercio de Lima - Sector Textil e Indumentaria Elaborado por López (2016) 
Ocasionando el impacto negativo que sufrieron las empresas Agentes Intermediarias Textiles (2011-2016), la cual se explica a continuación:

2011: Presentaba 22 empresas activas, 01 empresa con suspensión temporal de actividades quedando 21 empresas operativas.

2012: De las 21 empresas activas, se incrementa 04 empresas que inician operaciones en ese año, siendo 25 empresas a esa fecha,

2013: Contándose con 25 empresas activas, se adicionan 02 empresas, llegando a operar 27 empresas en ese año

2014: De 27 empresas activas, se aúna
01 empresa, llegando a 28 empresas en total, de las cuales en ese mismo periodo, 09 de ellas presenta la suspensión temporal de actividades, quedando 19 empresas en ese periodo

2015: De las 19 empresas activas, se adiciona 01 empresa más; no obstante, 01 empresa presenta suspensión temporal en ese año, contándose con sólo 19 empresas operativas hasta ese año 2016: Siendo 19 empresas activas, ese año 02 empresas presentan suspensión temporal, llegando a 17 empresas Agentes Intermediarias Textiles operativas.

Donde se estima que las empresas Agentes Intermediarias Textiles exis- tentes, disminuyeron como consecuencia de las siguientes situaciones:

1. Ocho empresas con deuda tributaria por IGV

2. Tres empresas con Baja de Oficio

3. Una empresa con baja definitiva (en liquidación)

4. Dos empresas con suspensión temporal

5. Diecisiete empresas Activas

Esta situación presentada, también desfavorece a las empresas confeccionistas exportadoras los cuales, presentaron al año 2016 a 137 empresas exportadoras de prendas de vestir de categoría t-shirt (ver Figura 6).

\section{PAÍSES DESTINOS DE EXPORTACIÓN DE PRENDAS DE VESTIR DE ALGODÓN: CATEGORÍA T-SHIRT-AÑO 2016}

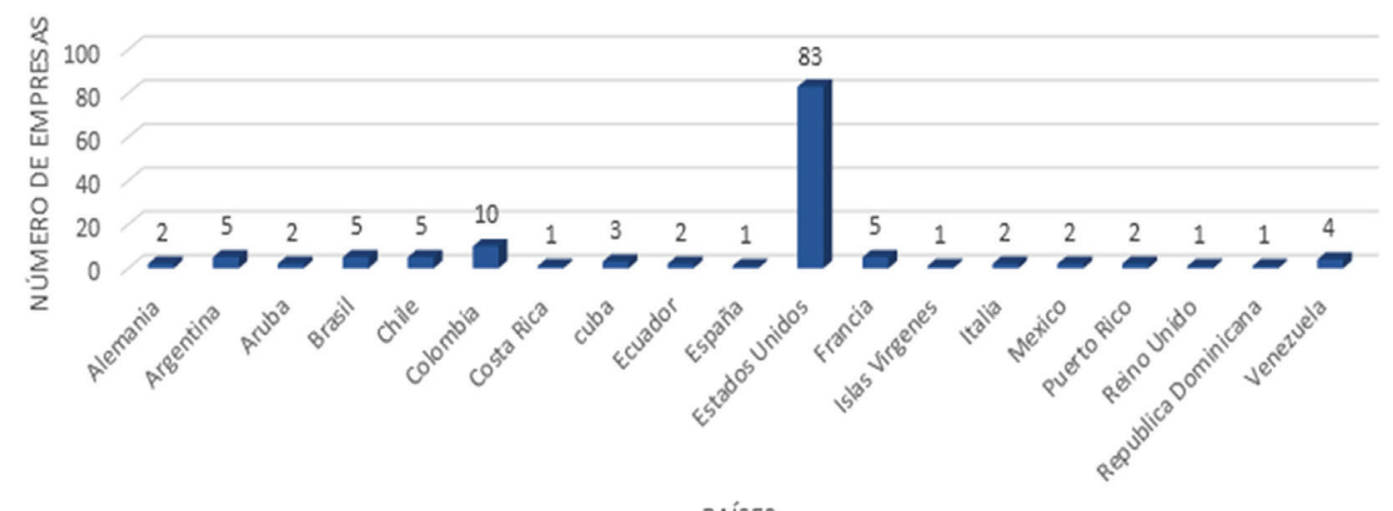

PAÍSES

Figura 6. Países destinos de Exportación de Prendas de Vestir de algodón: categoría T-Shirt año 2016

Fuente: Comisión de Promoción del Perú para la Exportación y el Turismo -Promperú / Elaboración propia

Lo cual refleja, que las 17 empresas agentes intermediarias textiles, han generado 137 empresas confeccionistas exportadoras (ver figura 5), siendo la proporción de $137 / 17=8$ fábricas confeccionistas

Interpretando que cada empresa Agente Intermediario Textil, origina la actividad exportadora de nueve (8) empresas confeccionistas.

\section{DISCUSIÓN}

Del análisis realizado y resultados obtenidos a las comisiones por servicios de los Agentes Intermediarios Textiles, representantes de empresas del exterior, se encuentran inafectas al Impuesto General a las Ventas, no existen estudios, en donde se muestren una relación al tema investigado, no existe otros estudios que sean muy similares o parecidos. En este contexto, el presente estudio sugiere que dichos servicios por comisión, sean incluidos en la norma del Impuesto General a las Ventas, en el apéndice V Exportación de Servicios.

Para que sea posible la exportación de prendas de vestir, es necesario la pre- 
sencia de las Empresas Agentes Intermediaria Textiles, con la finalidad que la exportación de prendas de vestir sea de óptima calidad.

La carencia de inclusión en el marco normativo de la Ley del Impuesto General a las Ventas, Apéndice V Exportación de Servicios; de las Comisiones de los Agentes Intermediarios Textiles, representantes de empresas del exterior, genera controversias de interpretación tributaria conllevando al perjuicio económico a las empresas de este tipo.

Al gravar con el Impuesto General a las Ventas los ingresos por comisiones, se distorsiona el rendimiento económico de la empresa (ingreso) y disminuye el beneficio económico con el tributo asumido.

Las comisiones por servicios por los Agentes Intermediarios Textiles, por no estar en el marco normativo Apéndice $\mathrm{V}$ exportación de servicios de la Ley del Impuesto General a las Ventas, ocasiona la carencia de Empresas Agentes Intermediarias Textiles y repercute en la existencia de Empresas confeccionistas perjudicando las exportaciones.

\section{REFERENCIAS BIBLIOGRÁFICAS}

Alva, M. (2011). IGV Análisis Práctico del impuesto General a las Ventas. Lima: Pacifico Editores.
Alva, M. (2013). Manual práctico del impuesto General a las Ventas. Lima: Pacifico Editores.

Burgos, E. (31 de agosto del 2013) La Hipótesis de Incidencia en el caso del Impuesto General a las Ventas. Recuperado de http://solucionescontablestrujillo.blogspot.pe/

Beaumont, R. (2010). El código de Comercio de 1902 y el proyecto de ley marco del empresariado aprobado por la comisión de Justicia del Congreso de la República. Recuperado de https:// www.pj.gob.pe/wps/wcm/connect/ cij/s_corte_suprema_utilitarios/as_ home/as_publicaciones/as_cuadernos/as_cuadernos8

Poder Ejecutivo. (1994, 07, 24). Ley de Comprobantes de Pago. (Ley $\mathrm{N}^{\circ}$ 25632). DO: Diario Oficial el Peruano.

Poder Ejecutivo. (1999, 04, 15). Texto Único Ordenado de la Ley del Impuesto General a las Ventas e Impuesto Selectivo al Consumo. (D.S. N 055-99-EF). DO: Diario Oficial el Peruano.

Poder Ejecutivo. (2016, 06, 22). Inclusión de operaciones en el Apéndice $V$ Exportación de Servicios. (D.S. $\mathrm{N}^{\circ}$ 164-2016-EF). DO: Diario Oficial el Peruano.

De la Fuente, M. y Echarri, A. (1999). Modelos de Contratos Internacionales (Tercera edición): Madrid Fundación Confemetal.
Poder Ejecutivo. (2011, 01, 01). Ley de Fomento al Comercio Exterior de Servicios. (Ley N ${ }^{\circ}$ 29646). DO: Diario Oficial el Peruano.

Ministerio de Economía y Finanzas. (2014). Normas Internacionales de Contabilidad $N^{\circ} 18$ Ingresos de Actividades Ordinarias. Recuperado de https://www.mef.gob.pe/contenidos/ conta_publ/con_nor_co/vigentes/ nic/18_NIC.pdf

Obregón, R. (2012). Modelos de Contratos Internacionales. Departamento de Facilitación de Exportaciones Promperú, recuperado de http://www. siicex.gob.pe/siicex/documentosporta 1/469767587rad790CB.pdf

Villanueva, D. \& Gutiérrez, W. (2014). Tratado del IGV regímenes general y especiales. Lima: Pacifico Editores SAC. 